\title{
UNA CARACTERIZACIÓN DEL HUMOR VIOLENTO EN LA ENSEÑANZA UNIVERSITARIA
}

\section{A CHARACTERIZATION OF VIOLENT HUMOR IN UNIVERSITY TEACHING}

\author{
Anna María Fernández Poncela ${ }^{1}$ \\ https://orcid.org/0000-0003-3080-212X
}

Recibido: mayo 6, 2021 - Aceptado: mayo 28, 2021

\section{RESUMEN}

El objetivo general de este texto es revisar el humor violento a través de teorías y funciones del humor, en primer lugar. En segundo lugar, y en concreto, realizar una caracterización de los tipos o las formas, y las expresiones o los modos, en su práctica cotidiana en general, y especialmente en la enseñanza aprendizaje. Esto se realizó con la participación de jóvenes universitarios que expresaron opiniones y relataron experiencias, a través de una encuesta de grupos de enfoque y de narraciones. Como principal resultado es posible afirmar la vigencia del humor violento e incluso su magnitud en nuestros días, en la vida y en el espacio educativo.

Palabras clave: humor, características, teorías, expresiones, experiencias.

\section{ABSTRACT}

The general objective of this text is to review violent humor through theories and functions of humor, first. Second, and specifically, to carry out a characterization of the types or forms and the expressions or modes, in their daily practice in general and especially in teaching-learning. This is done with the participation of young university students who express opinions and relate experiences, through a survey, focus groups and narratives. As the main result, it is possible to affirm the validity of violent humor and even its magnitude in our days, in life and in the educational space.

Keywords: Humor, Characteristics, Theories, Expressions, University, Experiences.

1 Doctora Cum Laude en Antropología Cultural, Universidad de Barcelona, España. Profesora-investigadora, Universidad Autónoma Metropolitana. Investigadora y docente titular C, tiempo completo, UAM-X. Miembro del Sistema Nacional de Investigadores, nivel 2. fpam1721@correo.xoc.uam.mx 


\section{INTRODUCCIÓN}

Hoy se cuenta con varias investigaciones en torno a la importancia del humor y la risa, referidas a la salud y la vida. En general, todas subrayan sus beneficios y pocas apuntan la existencia también de posibles perjuicios, o solo los mencionan sin abordarlos. El humor benigno y benéfico aporta equilibrio a la persona y sus relaciones sociales, ya que fomenta una actitud positiva ante el mundo y la vida. Sin embargo, ¿qué acontece con el humor violento?

El objetivo de este trabajo es precisamente hacer una revisión de los perjuicios del humor, sus enfoques y funciones. Lo que incluso podría llamarse la cara oculta del humor o la cara oscura, pese a que está más que clara y visible -desde la teoría hasta la experiencia- en la cotidianeidad, como se demostrará. También se revisan sus funciones, tipos, modos. Todo ello y de manera especial en el espacio escolar, con el estudio de caso en el ámbito universitario.

De hecho, el humor -con el inicio de la educación y la exposición a la cultura, socialización formal e informal-, adquiere connotaciones que a veces pueden ser violentas, y que la sociedad permite e incluso fomenta, consciente o inconscientemente.

\footnotetext{
La risa de un niño pequeño nunca es burlona. Es una risa bella, pura, una risa de complicidad, de intimidad. Los bebés no se ríen de la gente, se ríen con la gente. Lo que les hace romper a reír es la relación. Les encantan los juegos, las carantoñas, las miradas que se gustan. Cuando crecen un poco, los niños se ríen mientras corren, juegan al escondite, se empujan, etcétera. Son risas compartidas. $\mathrm{Y}$ de adolescentes siguen riendo por cualquier cosa, se abandonan a descontroladas risas comunicativas; ríen en grupo, ríen por el simple hecho de estar juntos. Su complicidad salpica a las personas mayores, que ya no saben divertirse y que, para defenderse, consideran «tonta» la risa de los jóvenes. Por lo general, los adultos no saben reír juntos por el simple hecho de sentirse cómplices, de estar en la intimidad. Necesitan que les gasten una broma, se ríen de los demás o de sí mismos (Filliozat, 2007, p. 201).
}

La relevancia de la investigación es describir y analizar el humor violento en la universidad, no solo su hostilidad y agresividad -que va de lo molesto a lo cruel-, sino también sus perjuicios, mismos que se insertan en la mente y emoción humana, se graban en la psique y se convive con ello al parecer mucho más tiempo después del momento de la burla o el chiste grosero, como se expondrá en varios ejemplos y experiencias narradas. Si bien, como se sabe, el humor en general es benéfico de muy diferentes maneras (Fernández, 2016), para el proceso enseñanza aprendizaje, lo que no se conoce tanto -o no se ha investigado- son las funciones, las características y los efectos del humor violento, como se expone en este estudio y se presentará a lo largo de estas páginas.

Cuando reiteramos [la burla, el chiste], se hiere psicológicamente, y la ofensa o el efecto perduran más allá del espacio educativo y de la etapa de vida en la cual se produjo el suceso. Se trata de un humor violento que se practica -desde el profesorado al alumnado y viceversa, así como entre el estudiantado- por motivos de origen geográfico o sexo, además de su perjudicial presencia y auge en las redes, en fechas recientes. 


\section{EXPOSICIÓN METODOLÓGICA}

La parte práctica de la investigación tuvo lugar en la Universidad Autónoma Metropolitana (UAM) sede Xochimilco, Ciudad de México, en el año 2018, a través de varias técnicas de investigación, con una encuesta -con 558 casos- que enmarca cuantitativamente el uso y los tipos de humor por parte del profesorado en la universidad, desde la mirada del estudiantado.

El tema se profundiza, amplía y enriquece con los testimonios de cuatro grupos focales y las narraciones individuales del estudiantado de dicho centro de educación superior, que expresan y reflexionan sobre sus experiencias. En total participaron 54 personas en los primeros y 64 personas en los segundos. Se trata de un estudio descriptivo y exploratorio con enfoque interpretativo, que presenta la libre expresión de ideas, según los asuntos seleccionados (Ruíz, 2012).

El trabajo consiste en buscar y encontrar sentido a la información obtenida a través de expresiones sobre experiencias -organizadas en categorías y subcategorías-, según el análisis de contenido temático empleado de forma muy general (Andreu, 2002). En la participación se reflexiona colectivamente sobre lo central de esta investigación: el humor violento. Esto último, algo importante a destacar ${ }^{2}$.

\section{APROXIMACIONES TEÓRICAS}

$\mathrm{Al}$ investigar sobre las teorías del humor y la risa, aparece una que llama la atención para los objetivos puntuales de este texto: la teoría de la superioridad. Varios autores señalan, en general, tres o cuatro; entre las principales: la incongruencia, la liberación de tensión y la teoría de la superioridad, aunque hay quien añade la del juego. La teoría de la superioridad, ya mencionada en los griegos clásicos, subraya la «superioridad» de un ser humano sobre otro, a través de la malicia, la burla y el desprecio; una suerte de humor agresivo y violento, entre cuyos discursos sobresale el racismo, el sexismo, el clasismo, la intolerancia hacia creencias distintas y los comportamientos diferentes (desde la discriminación y el no reconocimiento personal, hasta lo social y cultural, entre otros) (Carbelo, 2006; Fernández Poncela, 2016).

Una de las funciones del humor es la de crítica social: válvula de escape, protectora y $\operatorname{agresiva}^{3}$ (Ziv, 1984). En el proceso de enseñanza aprendizaje sobresale la pedagógica, creativa, de diversión, distensión, motivadora y de camaradería, además de que puede ser agresiva (Fernández Solís, 2009). Como se observa, se superponen algunas ideas con las teorías. En todo caso, resalta la social como vínculo que une a la gente a reírse de lo mismo, cohesionando al grupo. No obstante, a veces, puede reafirmar un «nosotros», a costa de los «otros» (Tajfel, 1984); una suerte de consenso y protección de unos, y de agresión hacia otros. Lo agresivo y hostil es válvula de escape, en el sentido de expresión del pensamiento tabú o políticamente incorrecto: una suerte de liberación controlada (Freud, 2008).

2 Añadir que en cada sub apartado se amplía un poco más la metodología utilizada en la investigación cuyos resultados se presentan en este artículo.

3 En la literatura sobre el tema, se habla casi siempre de agresión -también hostilidad y violencia-, que aquí se retoma y así se nombrará. Sin embargo, hoy en día existen corrientes que subrayan la necesidad de separar agresión de violencia. La primera, más biológica, ligada a la sobrevivencia compartida por todos los animales; la segunda, más cultural y propia del ser humano. 
En cuanto al aspecto de protección, el humor funciona como recuperador de tragedias y traumas, a modo de defensa contra el miedo (Berger, 1999). El humor agresivo se ríe de algo o de alguien desde una supuesta posición de superioridad; hunde su origen en la agresión que busca degradar, humillar al otro, también desde la frustración que persigue la recuperación de la superioridad o el control de la situación (Ziv, 1984). Se habla incluso de la risa como arma (Berger, 1999), empleándola con objeto de causar daño, producto de ciertos tipos de humor, y por supuesto, en consonancia con la teoría de la superioridad.

Autores como Freud (2008), al referirse al humor, y más concretamente al chiste -si bien puede hacerse extensivo a otras formas humorísticas- señala «el papel que el chiste desempeña a favor de la tendencia hostil». Y añade: «La hostilidad violenta, prohibida por la ley, ha quedado sustituida por la inventiva verbal [...], emplear contra nuestro enemigo el arma del ridículo» (2008, p. 100). Los chistes ofensivos y tendenciosos pueden dirigirse a "superiores provistos de autoridad», lo mismo que a personas de «menor valor y más indefensas» (2008, p. 102). Todo ello relacionado con «los deseos y anhelos de que los hombres tienen un derecho a hacerse oír al lado de las amplias y desconsideradas exigencias de la moral» (2008, p. 108).

Existe pues, en primer lugar, el humor considerado ingenuo, benigno, blanco o bondadoso, llamado «afiliativo» según diferentes autores, tales como Berger (1999). El humor benigno:

A diferencia del ingenio, no impone excesivas exigencias intelectuales. A diferencia de la ironía y de la sátira su finalidad no es atacar. A diferencia de las creaciones extravagantes de la «locura», no presenta un «contra-mundo». Al contrario, es inofensivo, inocente incluso. Su finalidad es generar placer, distensión y buena voluntad. Fortalece el fluir de la vida cotidiana en lugar de alterarlo [...]. En esta encarnación, lo cómico funciona, por lo tanto, como una diversión suave y absolutamente sana. Es bajo esta forma que «el humor es la mejor medicina», como dice el Reader's Digest. El humor benigno es la expresión más común de lo cómico en la vida cotidiana. Proporciona la diversión ligera que ayuda a pasar el día y a superar las pequeñas irritaciones (Berger 1999, p. 170).

Este autor, en su libro sobre la risa, habla también del humor no tan benigno: la sátira -un tipo de humor belicoso-que «es el uso deliberado de lo cómico con fines agresivos [...] la intención agresiva se convierte en motivo central de la expresión cómica [...] [al] constituir un arma» (1999, p. 255). La sátira posee un tono emocional malicioso y se dirige contra individuos, instituciones y sus representantes, o contra grupos sociales o culturas enteras.

En su famoso ensayo, Bergson menciona la risa, entre otros temas, como «una corrección. Hecha para humillar, debe comunicar una impresión penosa a la persona que es objeto de ella». Es más «no puede ser absolutamente justa [...] tampoco puede ser buena. Su función es intimidar, humillando» (2008, pp. 137-138).

La risa es producto del humor y el humor es la capacidad de percibir algo como cómico. Se trata de una reacción fisiológica que también incluye una descarga física y psíquica, por lo que parece benéfica, incluso si la produce un humor hostil y agresivo (Fernández Poncela, 2016) ${ }^{4}$.

4 Madan Kataria, autor de Yoga de la risa apunta que, para provocar la risa, a veces se cuentan chistes ofensivos. [Él creó un método, a través de ejercicios y técnicas, para ejercitar naturalmente: «la risa del cuerpo»] (Kataria, 2012). 
El humor agresivo y doloroso, puede provocar daño en varios niveles psicológicos: «La risa puede ser un arma, como ocurre particularmente en el contexto de la ironía y la sátira» y es que, como escribe Berger (1999):

La capacidad de ver las cosas desde una perspectiva cómica no es necesariamente una cualidad moralmente admirable. La aptitud para lo cómico puede emplearse para una serie de objetivos moralmente reprochables [...] el ingenio se puede ejercer con malicia y puede ir asociado a una actitud de nihilismo moral (p. 75).

Como resumen del humor «negativo», «peligroso» o "violento», podemos señalar que existe una serie de acciones o cuestiones de carácter humorístico que, sin negar su contenido entretenido y divertido, pueden considerarse como discriminatorias y violentas; en todo caso, en algún punto y nivel, negativas. La broma, la burla, la ironía, el ridículo, el sarcasmo y la sátira, con toda su inteligencia mental e ingenio cognitivo, así como con sus resultados benéficos de descarga de energía implican, de alguna manera y en cierta medida, violencia y agresión; se pretende humillar y herir en diferentes grados, y a través de expresiones diversas, crear inferioridad a quien se destina dicho humor y también generar una suerte de venganza y superioridad, cuando no de resarcirse del dolor de quien se cree lo provoca.

Entre los tipos de humor violento destacamos aquí la broma, y sobre todo la burla, por ser habitual en nuestra sociedad. La broma es una suerte de maniobra, trampa o truco. «Cosa que se dice, hace $u$ ocurre que parece sin importancia, pero resulta cara o de consecuencias desagradables [...]. Alegría y diversión de la gente en una reunión» (Moliner, 2001, p. 417). Por supuesto, existen bromas más benignas que otras, pero las hay hostiles y "pesadas», que denigran y dañan.

La burla también es violenta. Sin embargo, algunas estrategias burlescas son utilizadas para exorcizar psíquicamente los enfrentamientos: en varias culturas, la risa libera el espíritu o busca vencer a la muerte (Planchart, 2009). La burla ridiculiza. La ironía suele ser una burla disimulada. El sarcasmo es una burla dura. Se trata siempre de colocar al otro en una situación ridícula, inferior que lo humille y denigre (Spilzinger, 2002), que reste o niegue valor a una persona o situación (Portilla, 1997). Es signo de violencia potencial. Exorciza psíquicamente los enfrentamientos. Sea defensa, como se ha dicho, o ataque $-\mathrm{o}$ las dos cosas a la vez-, la burla suele señalar aspectos del otro que dañan, duelen y pueden tener consecuencias de diversa índole.

Se trata de la «Acción, ademán o palabras con que se procura poner en ridículo a alguien o algo. 2. chanza. 3. engaño. 4. bromas o mentiras [...]» (RAE, 2020).

Acción o palabras con que se trata a una persona o una cosa como digna de risa o se las convierte en objeto de risa [...]. Desconsideración que puede tomarse como desprecio [...]. Engaño hecho abusando de la fe del engañado. Broma (Moliner 2001, p. 429).

Descartes (2003) afirma que la burla

[...] es una especie de alegría mezclada con odio, que se produce al ver algún pequeño mal en una persona a la que se cree digna de sufrirlo: se siente odio por ese mal, se siente alegría de verlo en quien lo merece; y cuando esto ocurre inopinadamente, la sorpresa de la admiración origina la risa, como dije al explicar la naturaleza de la risa. Pero ese mal debe ser pequeño; pues si es grande, no se puede creer que el que lo padece lo merece, a no ser que se tenga una mala índole o que se odie mucho a la persona en cuestión (p. 79). 
Bromas y burlas, ironías y sarcasmos, chistes y dichos que en su contenido causan y despliegan dolor teñido de humor, se emplean -consciente o inconscientemente-como arma arrojadiza contra el prójimo o contra uno mismo. Este humor que enfatiza diferencias, se basa en la agresión; no es lo mismo «reírse con», que «reírse de» (Martín, 2007).

Aquí se abordan cuestiones, teorías, funciones, tipos y modos del humor en general. De forma particular nos referiremos al humor violento, a través de un estudio concreto que refleja la práctica de su existencia y su empleo en nuestros días, y concretamente, en el espacio educativo.

\section{ACERCAMIENTOS EMPÍRICOS}

Tras la revisión de enfoques y reflexiones en torno a obras y autores sobre el humor violento, y buscando aterrizar estas ideas, presentamos información y datos sobre el mismo, a través de la mirada y la voz de jóvenes estudiantes universitarios y de acercamientos empíricos al tema por medio de una encuesta, de grupos focales y narraciones. Como se señaló, las tres técnicas de investigación social aplicada tuvieron lugar en la UAM/X, en el año 2018, con el alumnado de licenciatura de esa casa de estudios.

\subsection{Algunos datos sobre una encuesta ${ }^{5}$}

En primer lugar, la encuesta representativa de la comunidad estudiantil universitaria ofrece un panorama amplio general, así como cifras concretas sobre el empleo del humor y la risa por parte del profesorado, según el alumnado, y permite conocer los tipos de humor empleados ${ }^{6}$.

Si bien su temática es más amplia que la de este texto, hubo preguntas circunscritas a los objetivos que aquí se persiguen. Primero, se cree que los profesores siempre usan el humor $(30.5 \%)$ o lo hacen a veces $(57.21 \%)$, en total $87.71 \%$, la mayoría lo emplea.

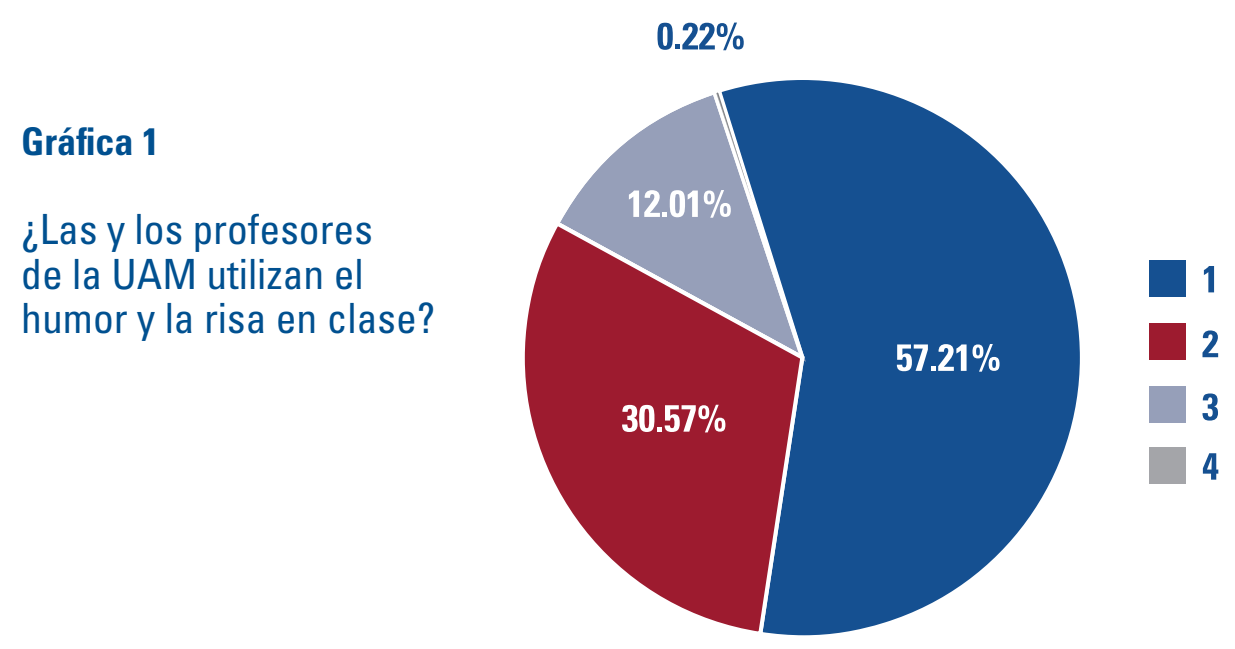

Fuente: Encuesta sobre la risa, UAM/X, 2018.

5 Se aplicó a 558 estudiantes de licenciatura, distribuidos porcentualmente según el universo, por carrera y por división, el margen de error es +- 4.5 y el nivel de confianza de $95 \%$.

${ }_{6}$ Este apartado se circunscribe al empleo del humor por parte del profesorado en el aula universitaria, y según percepciones y opiniones estudiantiles. 
$\mathrm{Al}$ interrogar sobre para qué lo hacen, la respuesta giró en torno a considerar que es una técnica o medio de mejorar el aprendizaje $(41,79 \%)$, o porque así son ellos $(34,83 \%)$ (gráfica 2). Aquí surgen diferencias, siempre desde la visión del estudiantado, entre quienes lo utilizan consciente e intencionalmente, y quienes lo emplean como parte de su personalidad.

Gráfica 2

¿Para qué lo hacen?

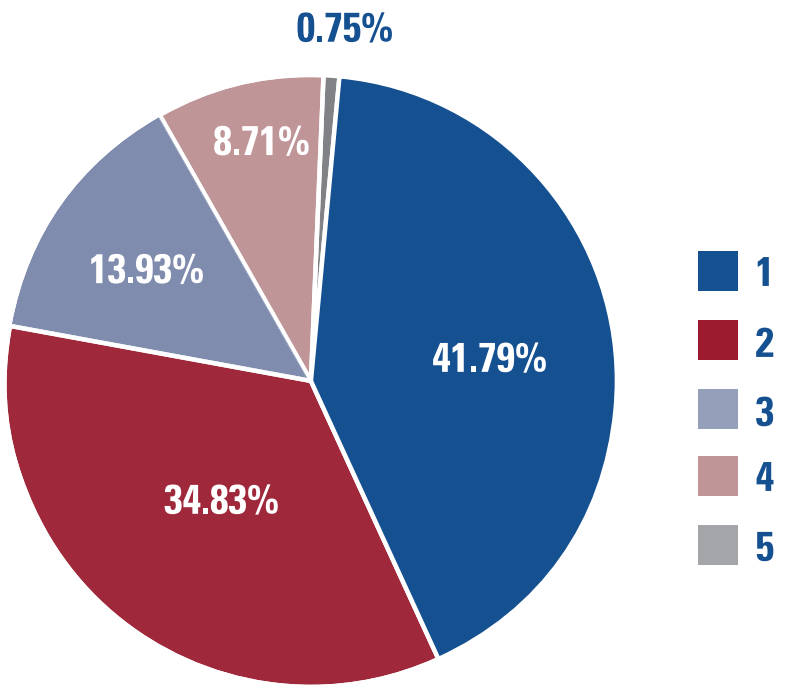

Fuente: Encuesta sobre la risa, UAM/X, 2018.

Al indagar cómo emplean el humor, aparece -de forma insinuada o directamente- el tipo de humor violento. Los estudiantes señalan de manera general: comentarios humorísticos $(34,94 \%)$ de los cuales no es posible saber su contenido, y anécdotas que se cuentan en clase $(29,80 \%)$, donde acontece lo mismo. Además también se habla, de manera específica, de las burlas $(5,98 \%)$ y los chistes tendenciosos $(5,88 \%)$. En este punto ya claramente con contenido agresivo (gráfica 3). Todo esto se irá aclarando, ampliando y profundizando, con las técnicas cualitativas que se presentan a continuación.

\section{Gráfica 3}

Las y los profesores que sí utilizan el humor y la risa ¿cómo lo hacen? (Varias respuestas).

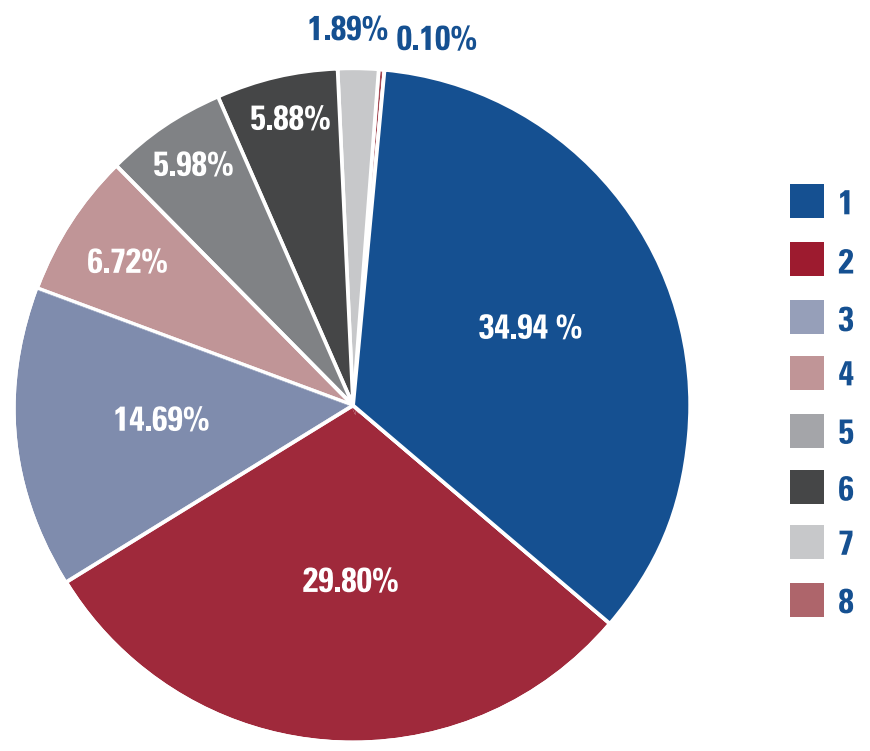

Fuente: Encuesta sobre la risa, UAM/X, 2018. 
Aquí la encuesta comprueba lo que se suponía, imaginaba o sabía, y que se reafirmará con ejemplos en el siguiente apartado: que existe un humor violento en la educación y concretamente referido de los docentes hacia los estudiantes ${ }^{7}$.

En fin, «las formas de humor agresivas son bastante comunes en el aula» (Siurana, 2015, p. 124). Este autor, basándose en varios estudios en el espacio educativo, afirma:

[...] la mitad de todos los casos de humor implicaba[n] reírse de una persona, de un grupo de gente o de una institución. Hasta un 20 por ciento de todos los comentarios humorísticos de los educadores se burló de un estudiante individual o de la clase en su conjunto (Gorham y Christophel, como se cita en Siurana, 2015, p. 124).

Y las consecuencias del humor agresivo en el aula son la inhibición, el conformismo, el temor del alumnado a ser ridiculizado por el profesorado (Janes y Olson, como se cita en Siurana, 201, p. 124), entre otros temas que se irán desplegando a continuación.

\subsection{Información y testimonios a través de grupos focales y en narraciones ${ }^{8}$}

En segundo lugar, con objeto de ahondar los datos generales, y sobre todo describir y explicar con más detalle, se realizaron cuatro grupos focales. También se solicitaron narraciones individuales como complemento informativo a universitarios de nivel licenciatura de la UAM / $X^{9}$, como parte de un estudio descriptivo exploratorio e interpretativo, logrando la obtención de experiencias compartidas (Ruíz, 2012). La revisión de ambas fuentes se realiza a través del análisis de contenido temático general, con la información cualitativa obtenida en los grupos y las expresiones recabadas (Andreu, 2002), para ordenar y organizar una mirada significativa y profunda en torno al tema que centra esta investigación. Las indicaciones sobre los puntos a abordar fueron: si existe un tipo de humor que violenta; cómo y de qué manera se expresa; por qué y para qué se emplea, y la solicitud de ejemplos de vivencias concretas en la vida, y sobre todo, en la universidad ${ }^{10}$.

Grosso modo la mayoría afirmó la existencia de dicho tipo de humor. A continuación, se expresaron relatos en el sentido de las formas en que se utiliza de manera general, las causas, la intención y las consecuencias, todo ello además de las ilustraciones con casos reales.

7 Comentar que, si bien la encuesta tomó en cuenta la variable «sexo», para el caso que nos ocupa, apenas aparecieron diferencias significativas en las respuestas obtenidas.

8 Se aplicaron cuatro grupos focales a estudiantes de diversas carreras. En total el número fue de 54 personas participantes. Las narraciones fueron realizadas por 64 estudiantes en total. Tras la transcripción testimonial se adjunta el sexo $-h$ para los hombres y $m$ para las mujeres- y la edad.

9 En este punto se estudia el humor en general y el humor en la educación. Al tratarse de universitarios, la mayoría de los testimonios provienen de su experiencia en las aulas; sin embargo, también aportan expresiones en otros espacios de sus vidas.

10 Además del análisis, lo que interesa es mostrar los testimonios y las expresiones directas. Si bien se realizó una selección de las transcripciones, se tomó la decisión de presentar varias de ellas, con objeto de que sean las protagonistas del análisis, la interpretación y revisión y quienes se expresen; y no al contrario: como ejemplo sucinto y comprobatorio de una teoría o ideas previas sobre el tema. 


\subsubsection{Formas o tipos}

En cuanto a formas o tipos en que se expresa, se habla de él en lo psicológico, mental, verbal oral o escrito, en la cotidianeidad presencial y en las redes sociales, y en lo emocional en todos los sentidos:

- «Puede presentarse de manera física y psicológica» (h 18).

- «También la verbal [...] insultos o comentarios vejatorios» (h 18).

- «Puede ser de dos maneras: la verbal y la escrita; ya sea en algún lugar en específico o en las redes sociales, a través del insulto y la humillación» (h 20).

- «De manera emocional, psicológicamente e inclusive física[mente]» (m 21).

\subsubsection{Modos o expresiones}

Sobre modos o expresiones, se aludió a las bromas pesadas y humillantes, los comentarios hirientes, vejatorios o despectivos, insultos, burlas y chistes (además de comentarios de doble sentido, ironía o sarcasmo):

- «Herir sus sentimientos por algún comentario» (h 19).

- «Comentario ofensivo o broma hacia una persona» (m 20).

- «Bromas de mal gusto sobre algo que incomode a la persona» (h 20).

- «Se da por burlas y humillaciones» (h 19).

- «Burlas de cosas feas» (h 20).

- «Usando el sarcasmo contra alguien» (h 24).

Entre los ejemplos aparecen: «El típico compañero de primaria que hacía bromas pesadas con todos. Era gracioso, pero al final de cuentas, violento» (h 18); «Bullying entre compañeros de clase» (h 21); "Cuando los temblores, hubo muchas bromitas; personas que estaban bañándose o durmiendo y le ponían la alerta sísmica y, pues al menos, a ellos les pudo causar gracia, pero a uno que lo vivió y que ya está como traumado, pues creo que sí le podría afectar» (h 20).

\subsubsection{Infancia y adolescencia en el recuerdo}

Otro ejemplo: «[...] en la primaria, a una niña con sobrepeso, los niños le hacían bromas: "ballena", "gordinflona". Inclusive, yo alguna vez seguí la corriente de esas burlas, pensando que se trataba simplemente de humor [...]. En la secundaria le decían "porka"; también formé parte de los que se burlaban de aquella niña, se reían si exponía, si se equivocaba, por el simple hecho de hablar» (m 20).

Varios testimonios recogieron experiencias de primaria, secundaria, bachillerato hasta llegar a la universidad, a veces con la misma persona objeto de burla, otras con anécdotas o asuntos disímiles. «En la primaria lo viví: no tenía nombre [...]. El principio del suplicio 
era lo que denomino «doble lunch», si no querías quedarte sin comer [...]. En la secundaria [...] defenderte de las burlas por la torpeza [...]. En el nivel medio y superior me trajeron un cambio de visión, pues de llorar simplemente, no sé cómo pasé a carcajearme, posiblemente influido por las redes sociales, esas que tanto nos hacen banales [...]. Un profesor al que respeto, a la cara te decía lo "menso" que te veía» (h 22).

En la primaria es cuando se ejercen, reciben o presencian las primeras manifestaciones de violencia en el grupo de pares, muchas veces con humor, producto de bromas y burlas. «La niña nueva [...] su rostro tenía rasgos peculiares [...]. La nombraban "la china" y hacían comentarios poco amables [...]. Aún no comprendía lo dolorosas que pueden ser las palabras y nunca le pregunté si le molestaba o hacía sentir mal los comentarios de los demás compañeros [...]. Las palabras pueden hacerte especial pero también herirte [...], espero que ahora esté tranquila y que aquellas palabras hirientes no la hayan permeado [...]. Espero que el compañero que la intimidaba, haya aprendido lo importante de las palabras y que se puede lastimar con ellas» (m 20).

Los recuerdos infantiles sobresalen en varios casos: «En la escuela muchas personas hemos sido objeto de burla, ya sea por parte de nuestros compañeros de clase o de los mismos maestros. Y de la misma forma, al ser algún compañero nuestra víctima de esos ataques, algunos no comprendemos la situación y nuestra reacción es reír ante los chistes crueles que les hacen gracia a ciertas personas; pensamos que es gracioso y que no afecta en nada a quien está siendo atacado» (m 20). Como se observa, aparece todo un testimonio memorístico y reflexivo comprensivo, autocrítico y de autoconciencia y civismo (Siurana, 2015).

La infancia y la adolescencia son claves, y así como las transcripciones presentadas en estas páginas, revelan que «a esa edad no era consciente de mis acciones y de las consecuencias que podían tener» (h 20). La autorreflexión surgió espontáneamente, al reflejarse y proyectarse, al escuchar el relato del otro y también atender al propio; apareció con fuerza al trenzar o contrastar opiniones, al encontrarse identificados con otras vivencias, al revivir las propias, al pasar de la vivencia simple a la experiencia organísmica [modo de valoración que no deja de evolucionar, de cambiar] (Rogers, 2007).

\subsubsection{Burlas a personas}

Aquí aparece una diferencia entre la burla agresiva directa hacia las personas, y los chistes tendenciosos y discriminatorios a terceros -es decir, a quienes no están presentes en ese momento-, destacando de forma considerable la primera:

- «Burlándose directamente de una persona» (h 21).

- «Burlándose de algo vergonzoso que realice la persona» (h 27).

- «Comentarios despectivos en forma de burla a alguna persona» (m 22).

- «Comentarios hirientes de sus rasgos físicos o cualidades» (m 19).

- «Agredir o tomar como gracioso los defectos de otros» (h 20).

- «Sobre la baja estatura, llamarlo "gnomo" o "duende". Para mí, eran solo palabras graciosas» (h 20).

- «Chistes que tengan contenido homófobo, racista, etcétera» (h 20). 
Como ilustración: «Teníamos en secundaria un compañero con discapacidad y le hacíamos burla» (h 19). O « agresión de género a una vecina por no saber manejar su automóvil» (h 19).

También aparece la discriminación, especialmente de los grupos supuestamente vulnerables, por sexo o edad, por ejemplo: machismo, racismo, homofobia, aspecto físico, creencias, defectos, gustos o ideologías; simplemente un juego entre el endogrupo y el exogrupo (Tajfel, 1984).

- «Discriminando, haciendo menos a ciertas personas con ciertos comentarios» (h 19).

- «Tomar como graciosos defectos de otro» (h 20).

- «Haciendo notar una diferencia física o [expresando] alguna manera de racismo» (h 22).

- «Ofendiendo intereses, ideologías, aspecto físico, creencias: violentando su dignidad» (m 20).

- «Chistes burlones referentes al físico, las creencias o a los gustos de algunas personas; a veces también sarcasmo» (m 20).

- «Chistes o comentarios en referencia a grupos vulnerables» (h 24).

\subsubsection{Burlas a grupos}

$\mathrm{Y}$ es que muchas son las veces que «se hacen ciertas bromas hirientes a grupos vulnerables como las mujeres [...] o en situaciones como el feminicidio [...], lo vamos normalizando y lo vamos viendo como algo cotidiano que nos da risa, pero eso afecta gravemente a algunos grupos» (h 20). «El humor violento no respeta edad, género, estatus, ni nacionalidad, y quien lo provoca tampoco; podemos encontrarlo en muchos lugares, en las caricaturas, en los medios audiovisuales, textos, Internet e incluso hay comediantes que incluyen el humor negro en sus Stand Up Comedy» (m 20).

Sobre los chistes a ciertos grupos sociales por el hecho de serlo, se describe el humor negro como «[...] resultado de años de violencia, racismo y discriminación; las diferencias culturales y el ingenio de algunas personas crearon este tipo de chiste, con el fin de entretener y hacer reír. El problema es que no se dan cuenta que no es gracioso para todos y que, diciéndolos, pueden generar muchos problemas y causar mucho daño a ese grupo de personas a las que hacen víctimas [...]. Desde mi punto de vista, existe una doble moral; el ser humano tiende a disfrutar de ver a otro ser humano sufrir, pues lo mismo pasa con el humor negro: es divertido hasta que es a ti al que afecta» (h 26).

Varios fueron los ejemplos, como «cuando realicé el servicio militar: los chicos solían molestar a otros por su orientación sexual, pues les parecía gracioso» (h 20); «Burlarse de alguien al punto que la situación se salga de control y se pierda el respeto» (h 25); «Poner apodos me parece una forma de humor violento, pues muchas veces la persona no está de acuerdo» (h 26); «Hacer chistes denigrantes de etnias, razas y nacionalidades; es denigración hacia otras personas, aunque eso realmente no me afecte» (m 25); «En la secundaria a una niña la molestaban mucho, le hacían bromas, le ponían apodos y le aventaban cosas, solo por un rato de risas» (m 20). 


\subsubsection{Humor negro}

En ocasiones más que comentarios o chistes violentos, se trata de humor negro, que también puede ser violento, pero con otras connotaciones: "Cuando se burlaban de los niños muertos en el Rébsamen ${ }^{11}$ » (h 20). «Chistes sobre los 43 desaparecidos ${ }^{12}$ » (h 21). «Memes del $19 \mathrm{~S}^{13}$ » (h 22); «Menospreciar a alguien en el salón por un defecto físico» (h 20); «Burlarse de un compañero por su apariencia o por cómo habla» (h 20); «En mi caso, una persona se burlaba de mis dientes diciéndome "comadreja" y a lo que yo contestaba de manera racial; el compañero era de descendencia afroamericana como [color] "chapopote"» (h 20); «Mi abuelo se burla de mi primo por ser gay» (m 19); «En primaria a una compañera la acosaban por su aspecto físico: tener los ojos rasgados» (m 19); «Al cambiarme de una secundaria privada a una pública, en mi primer día, mis compañeros me metieron en un bote de basura, claro que fue gracioso para los demás, pero para mí no» (m 20); «Cuando alguien me dice que soy muy pequeña y se burla de mi estatura» (m 20); «En ocasiones, por mi nacionalidad colombiana, me han llamado traficante» (m 20); «El clasismo: en un centro comercial, intentan comprar una chamarra, pero no les alcanza, así que un chico le dice que si no tienen no vayan y los llama "frijoleros" y "nacos", y todos empezaron a reírse» (m 20).

Y seguimos: «Hay gente que se sigue burlando sobre lo que pasó a las Torres Gemelas, sabiendo que mucha gente murió ahí y muchos familiares de aquí, y lo siguen diciendo. En ese entonces las redes sociales no estaban tan disparatadas, pero todos estaban en ese plan y ahora están usando lo de los " 43 ". O sea: ¿cómo puedes asociar un meme de los 43 o algo de los 43 con una celebración religiosa? ¿Alguna idea? Con el Miércoles de Ceniza. Es muy cruel, lo ves y dices “jok!”; el punto aquí sería saber hasta dónde: ya lo vi, ya me reí, me siento mal, bueno ya. No voy a colaborar para replicar, porque como dice la compañera, es muy hipócrita decir: "no, yo no me he reído", porque nuestra mente es así, asociamos todo, aunque no conozcamos del tema [...], o sea de que nos estamos burlando de la gente que está sufriendo, o sea gente que se burla del 2 de octubre ${ }^{14}$ » (h 20).

Es esencial subrayar la importancia cuantitativa de este tipo de humor que provoca risas o sonrisas cómplices -basado en la crueldad y la deshumanización-, ante catástrofes y tragedias de gran magnitud, como en estos relatos autocríticos se reconoce en varias ocasiones.

11 [Durante el sismo del 19 de septiembre de 2017, en Ciudad de México (7.1 grados Richter), el Colegio Enrique Rébsamen se derrumbó. En él se impartían clases para niveles preescolar, primaria y secundaria. Se convirtió en uno de los sitios emblemáticos de la tragedia].

12 [«El 26 de septiembre de 2014 no solo fueron asesinadas seis personas y desaparecieron 43 estudiantes de magisterio del sureño estado de Guerrero, sino que "cerca de 80 personas fueron masacradas y ocultadas en Iguala por los diferentes grupos delictivos y sus cómplices oficiales", sostuvo el fiscal general Alejandro Gertz Manero». Versa, María (26 de septiembre de 2020). AP Explica: Así va caso de los 43 estudiantes desaparecidos. Los Ángeles Times. https://www. latimes.com/espanol/mexico/articulo/2020-09-26/ap-explica-asi-va-caso-de-los-43-estudiantes-desaparecidos].

13 [El 19 de septiembre de 2017, México registró un sismo de magnitud 7.1, provocando la muerte de 369 personas en el centro del país, innumerables heridos y daños materiales. Cfr. ¿Qué ocurrió el 19 de septiembre de 2017 en México? Universidad Nacional Autónoma de México. http://ciencia.unam.mx/leer/652/-que-ocurrio-el-19-de-septiembrede-2017-en-mexico-].

14 [«El 2 de octubre de 1968, en la Ciudad de México se suscitó una terrible matanza [...], provocando la muerte de más de 300 personas. Fue la brutal culminación de delitos que podrían ser considerados contra la humanidad, perpetrados desde el gobierno de México en contra de los estudiantes a lo largo de ese año [...]». s/a. Matanza de Tlatelolco. https:// www.cndh.org. $\mathrm{mx} /$ noticia/matanza-de-tlatelolco]. 


\subsubsection{El caso de la UAM}

\subsubsection{Los foráneos}

Entre los testimonios vertidos sobre el tema, aparecieron casos particulares sobre la propia estadía en la UAM: los nombrados como «foráneos», es decir, personas que llegan a estudiar a la universidad, procedentes de otros estados de la República Mexicana: «El referirse a un compañero por su condición de "foráneo". Se usa con intención humorística, pero puede evolucionar a una forma de discriminación» (h 18); «Las burlas por ser foráneo» (h 19); «La discriminación hacia compañeros foráneos con chistes de mal gusto, que su objetivo es denigrar» (h 21); "El que llamen "foráneos" a los compañeros que no nacieron o viven en la $C D M X »(h 20)$; «El humor que ejercemos hacia las personas foráneas. A veces, nuestro humor crece tanto que discriminamos o los rechazamos por no ser citadinos, y caemos en un nivel de violencia que no es apropiado» (m 19).

La violencia no es hacia el exogrupo o los otros (Tajfel, 1984), sino al exogrupo del endogrupo.

\subsubsection{El físico}

Otro caso son las burlas entre compañeros por su aspecto físico, su manera de hablar, imagen, comportamiento o simplemente por ser como se es: «En segundo trimestre, un compañero tartamudeaba y todos se burlaban de él» (h 19); «Los comentarios burlescos a una compañera, respecto a su físico» (h 19); «Burlarse de un compañero que siempre tartamudeaba al estar nervioso; yo también me reía de él, sin percatarme al instante de que estaba cometiendo una agresión» (h 27); «Burlarse de un compañero por su estatura» (h 20); «Molestaban a un compañero por su forma de vestir y hablar; realmente eran muy groseros con él» (m 19); «Algunos compañeros se burlaron de una compañera, porque se había manchado su vestido con el período menstrual. Le dieron un apodo muy fuerte y aún la llaman así» (m 20); "A una amiga le hacen burla, porque en una fiesta tomó un poco de más; al otro día le hacían comentarios, aunque daban risa, ella se pudo haber sentido mal» (m 20); «Una pareja en la cual como iban en el mismo salón, el novio la molestaba durante clases con bromas de su corte de cabello o del lugar donde ella vivía» (m 22); «Un chico que era virgen y le hacían burla por eso; el chico lo tomaba a broma, pero llegó un punto en el que esos comentarios lo incomodaron» (m 22).

Recordemos que el humor es aquello considerado como cómico y gracioso, más allá de la moral, del bien y el mal (Berger, 1999), y que muchas veces lo morboso u hostil es incluso lo más gracioso y risible (Freud, 2008).

\subsubsection{El profesorado}

Tras las burlas entre compañeros, llegamos al empleo de las mismas, ahora por parte del profesorado hacia el alumnado. Los profesores que bromean o se burlan de algún estudiante: «Un profesor regañó a un compañero por no leer muy bien y lo hizo de manera irónica» ( $h$ 20); «En una ocasión un profesor se burló de mí por ser cristiano» (h 22); «Hay profesores que agreden al alumnado con sarcasmo» (h 24); «Nuestro profesor hacía comentarios despectivos cuando no respondíamos según quería» (h 26); «Una maestra hizo un comentario despectivo hacia uno de mis compañeros; algunos rieron, sin embargo, a algunos nos pareció inapropiado» (m 19); «Un profesor se refería a un compañero despectivamente, como "huevón”, 
porque en una exposición se puso nervioso y el maestro tomó eso como una señal de que no había preparado el tema, de ahí en adelante lo llamaba así» (m 20); «Un profesor se la pasaba burlándose de un compañero, porque no podía pronunciar ciertas palabras» (m 20); «La maestra le dijo a mi amiga: “¿Estás tonta o qué?”. De momento a los compañeros les causó un poco de gracia, pero la maestra no sabe que después a la niña le dio sentimiento y todo el día se la pasó llorando en su casa, porque a esta maestra le encanta hacerte sentir mal» (m 22); «Un profesor molestaba a un compañero en demasía, sobre su aspecto físico y por su falta de comprensión de algunos temas; esta situación a todo el salón nos causaba mucha risa automáticamente, como si estuviéramos de acuerdo con la burla que el profesor le hacía a nuestro compañero [...]. Eso solo me hace reflexionar hoy en día y estar en desacuerdo con las acciones cometidas por el profesor en contra de mi compañero» (m 20).

Reiteramos la importancia de concientizar el tema (Stevens, 2006) que, si bien no es el objetivo principal de esta investigación, sí hubo siempre y en todo momento una invitación a la introspección y a la reflexión, o reflexividad en cierto modo (Guber, 2012).

Y en dirección contraria, los estudiantes que se burlan de un profesor: «En otro trimestre, la mayoría arremetíamos contra un profe para hacer más amena la clase, debido a que hablaba muy lento» (h 20); «La mayoría de mis compañeros descalificaban y se burlaban de mi profesor por su edad y condición física; muchas veces las opiniones dirigidas hacia el grupo eran con la intención de burlarse de él y de los demás, mediante chistes y comportamientos burlones» (m 26). Por supuesto, también existen las burlas de estudiantes a docentes, no sin crueldad, aunque la mayoría de las veces indirectas u ocultas, sobre sus conductas o incluso condiciones físicas y mentales.

\subsubsection{Machismo}

Los chistes machistas son otra forma de humor violento entre estudiantes: «Contaban chistes sobre violencia machista, en contra de las mujeres, como [por ejemplo sobre] golpearlas» (h 20); «Escucho muchos chistes raciales y homófobos» (m 22); «Siempre escucho comentarios discriminatorios de toda índole: grupo identitario, gusto, religión, etcétera» (h 26).

También surgió, entre las parejas, el humor o el «bulling humorístico», como lo nombraron: desde el joven que molesta continuamente a su novia en clase, hasta el que se burla de la tez morena de ella cuando, en una fiesta, ella comenta que con el «flash» no saldrá bien la foto y él le contesta: «¿Y a ti qué, si solo se te verán los dientes?», etcétera.

\subsubsection{Enredados en las redes}

Las bromas en las redes son ya algo usual, por no decir masivo: «Bromas de varias cosas, como la diversidad cultural que existe en la universidad; esto puede ser violento para algunas personas» (h 21); «El Facebook de la comunidad estudiantil creado por los mismos estudiantes, el cual la mayor parte de las veces comentan unos de otros, haciéndose burla» (m 21); «Memes de los 43 de Ayotzinapa o del 2 de octubre» (h 22); «Un grupo del Facebook de la UAM, hace memes o burlas de algunos compañeros» (m 19); «En una ocasión compartí un meme que decía "cosas que se te pierden a lado de la cama" y estaba una botella de Coca-Cola con el nombre de Paulette, que es una niña que encontraron muerta a lado de la cama, y... o sea, pues la verdad, sí me reí, pero obviamente no es como que yo vaya a una junta con personas que están hablando de muertes de niños y yo voy a decir ese chiste» (m 24); «¿Nunca han visto "memes" de judíos y de nazis? Son muy crueles [...] pero 
lo hacen de una manera que pasa desapercibido totalmente [...]. Vi uno hace poco, era una foto de Anna Frank [...]: "El Führer me invitó a bañarme... yo era el jabón". Y me dio mucha risa, pero si ves cómo es triste que nos riamos de cosas muy feas de la humanidad, pero que lo pinten de una manera tan graciosa» (h 26); «Retomando el tema de los 43, me enteré que lo asociaban a una botella de licor, relacionando con que ya los habían encontrado» (m 19); «Con tan solo unas palabras se puede lastimar a mucha gente. Como lo del incendio en la guardería $\mathrm{ABC}^{15} \mathrm{y}$ un show de Platanito [cómico mexicano] que dijo [que era] Kentucky fried children [...], entendí que hay personas que no tienen respeto a nada ni a nadie» (h 20); «Algo que al subirlo [a Internet] lo consideraba como humorístico, a otras personas parece ser [que] les di un golpe bajo con eso; por ello es que no logramos coincidir en cuanto a nuestro pensar» (h 20).

Nuevamente el hacer conciencia, tener autocrítica y la intención de cambiar dichas prácticas, son asuntos que reaparecen con insistencia en el discurso compartido.

El tema de las redes fue reiterado en la discusión de los grupos focales y en la narración individual, y es que al parecer se observa mucha violencia, desde los chistes y memes a terceros que son de mal gusto, con mucho humor negro, hasta las burlas directas. «Por ejemplo, a las mujeres se les dice: "Hazme un sándwich, o burlas del 2 de octubre [...], [para] una persona que no vivió eso, puede dar risa, pero a otra le puede llegar el recuerdo de un amigo tirado [...], cosas que se pueden llegar a normalizar en las redes y ahí está el peligro [...] hay ciertos grupos más susceptibles» (h 22).

Se manifiesta la preocupación del humor agresivo en este espacio hoy tan habitual e importante, y especialmente para los sectores juveniles.

«En las redes, el humor puede generar daños o consecuencias psicológicas en una persona a raíz de una publicación, un tuit, un post, que vaya contra alguien o sus ideas. Hiere» (h 19). Y es que "pareciera que el objetivo del humor en las redes es lastimar a otra persona, sin tener consideración [...], ahora con redes, los comentarios llegan a diferentes lugares teniendo mayor alcance y permitiendo que, a través de una pantalla, se escude la persona que ofende y trata de avergonzar a los demás» (m 20). De hecho, existe el ciberbullying: «Es fácil que una persona cometa un error, alguien lo grabe y se vuelva "viral" en un par de horas. La vida de la persona cambiará por completo y no para bien; en vez de ser reconocido por sus capacidades o sus talentos y dones, será reconocido por un error cometido, y sometido a un sinfín de juicios morales impuestos por la sociedad que lo rodea» (h 22). No obstante, hubo quien terció: «Al estar en redes sociales tienes que estar consciente que te estás exponiendo a la burla, la crítica, el escarnio, a todo» (m 26).

Hasta aquí una amplia y detallada descripción de maneras y de modos, y algo importante a rescatar que se reiteró a lo largo de los testimonios presentados en este artículo: la reflexividad (Guber, 2011) de quien comparte su relato, de lo que vio, escuchó, participó, y hoy se da cuenta y cobra conciencia que, además de gracioso y provocar risa y diversión, causó daño y dolor, en una suerte de re sensibilización y re conciencia emotiva, cognitiva, cultural y social. La reflexividad (Guber, 2012) -como conciencia de quien investiga, con los sujetos participantes, actores protagonistas, agentes a su vez conscientes y la temática desplegadainvita al darse cuenta y compartir, reflexionar, tener la posibilidad y oportunidad de cambiar y mejorar.

15 [El 5 de junio de 2009, en el estado de Sonora, México, se incendió la «Guardería ABC», falleciendo 49 niños y resultando heridos 106, de entre cinco meses y cinco años de edad]. 


\section{CONCLUSIONES}

El objetivo de este trabajo es caracterizar el humor violento. Primero exponiendo obras y autores, enfoques y teorías, obteniendo un panorama general del mismo. Destacan las teorías de alivio en general, e incongruencia y superioridad principalmente, y de forma particular (Carbelo, 2006; Fernández Poncela, 2016). Por otra parte, se aprecian las funciones sociales, de crítica, distensión, motivación, creatividad, diversión y camaradería (Ziv, 1984; Fernández Solís, 2009), y también se incluyen las de protección y agresión (Filliozat, 2007).

Acto seguido se focalizaron las expresiones de humor agresivo, recabadas en el espacio de educación superior analizado, según la psicología y la sociología, y el perjuicio y dolor que este causa en sus diferentes formatos y direcciones. Bromas y burlas directas o chistes a terceros; ironía y sátira, burla y sarcasmo; desde la superioridad, venganza o defensa, consciente o no, cual arma arrojadiza (Berger, 1999), hacia personas con problemas, grupos considerados diferentes o externos, juzgados y condenados, la discriminación y deshumanización generalizada, y seguramente inconsciente.

Se expuso una investigación sobre el tema en el marco universitario: desde el uso y formas de humor por parte del profesorado -a través de un enfoque estadístico cuantitativo, donde se percibe ya el empleo del humor violento-, hasta las técnicas cualitativas aplicadas entre el estudiantado, grupos de enfoque y narraciones, que dan testimonio significativo sobre este tipo de humor entre ellos, lo mismo de y hacia los docentes, en redes, en la vida presencial cotidiana, en los diferentes niveles escolares en el pasado, y de forma detallada y honda en su actual presencia y tránsito por la universidad.

Desde la ridiculización a quien se percibe como distinto, hasta el humor morboso hacia hechos sociales, pasando por el humor con que el profesorado recibe al alumnado en el proceso de enseñanza aprendizaje, sin desconocer asimismo cómo el profesorado también es objeto de burla de los alumnos. En este punto es importante destacar los relatos experienciales universitarios que iluminan tipos y modos, memorias de etapas escolares, hasta llegar al momento presente; enumerando las burlas personales, discriminaciones sociales y el humor negro.

Particular atención merece el humor violento en la UAM, hacia los estudiantes foráneos, por el aspecto físico, el sesgo machista, destacando finalmente el sobresaliente papel de las redes que, al parecer, han multiplicado exponencialmente el humor negativo y violento, por su facilidad de uso y el cierto distanciamiento, extensión de espacio y velocidad de su transmisión.

Es vital remarcar que este tipo de humor agresivo para el sujeto o sector hacia el que va dirigido, es particularmente molesto o incluso doloroso, cuando se actúa sobre una persona o colectivo directamente; esto es, sobre quien recae la broma o la burla. Por otro lado, es algo posible de evitar, o en el caso que ya ha sido actuado, revisar, darse cuenta y ofrecer disculpas, con objeto de reparar el daño (en la medida de lo posible) y devolver el respeto que merece la persona o el grupo.

Es un problema social a enfrentar y solventar en todos los ámbitos donde este tipo de humor tiene lugar. En el caso del sistema educativo merece especial atención, a juzgar por los resultados de esta investigación, y debe ser abordado a través de sensibilidad, humanidad y conciencia. Más allá de sus consecuencias para un devenir satisfactorio del proceso de enseñanza aprendizaje global -o incluso en el proceso formativo de la persona, en especial-, quedan claros sus efectos negativos y disfuncionales en la psique individual, y en las relaciones intersubjetivas y grupales. 
Finalmente, dos aspectos a destacar. Primero, las burlas poco pedagógicas e irrespetuosas del profesorado, que hace necesario replantearlas desde una mirada ética sobre el tema (Siurana, 2015). En segundo lugar, el proceso de autoconocimiento y conciencia espontánea y reflexiva al que este ejercicio dio lugar, en el sentido de darse cuenta (Stevens, 2006); clarificar; hacer una autocrítica; comprender; y las propuestas para rectificar y cambiar; evitar estas actitudes en lo personal y en lo social; tomar una actitud comprometida hacia el compañerismo, el respeto, la convivencia, la aceptación, la integración de todos; elegir un humor benigno, afiliativo, divertido, propositivo y educado.

El tipo de humor que yo defiendo, es decir, el «humor ético», es positivo tanto para uno mismo como para los demás y, en el ámbito educativo, aporta los siguientes beneficios: reduce la tensión, el estrés, la ansiedad y el aburrimiento; mejora la relación estudiante-profesor; hace menos intimidatoria la clase para los estudiantes; hace divertido el aprendizaje, creando actitudes positivas hacia él; estimula el interés y la atención a mensajes educativos; aumenta la comprensión, retención cognitiva y rendimiento; promueve la creatividad y el pensamiento divertido. El humor ético convierte la mera transmisión de información en una interacción social entre humanos (Siurana, 2015, p. 125).

\section{REFERENCIAS}

Berger, P. (1999). Risa redentora. Barcelona: Kairós.

Bergson, H. (2008) La risa. Ensayo sobre la significación de lo cómico. Madrid: Alianza Editorial.

De Sousa, R. (1987). When Is It Wrong to Laug. In Monrreall, J. (Ed.) The Philosophy of Laughter and Humor, 226-249. New York: State University Press.

Descartes, P. (2003). Las pasiones del alma. http://bibliotecadigital.tamaulipas.gob.mx/ archivos/descargas/31000000385.PDF

Guber, R. (2012). Etnografía. Buenos Aires: Siglo XXI.

Fernández Solís, J. D. (2009). El valor pedagógico del humo. Revista Trimestral de la Asociación Proyecto Hombre, 44, 27-38.

Fernández Poncela, A. M. (2016). Humor en el aula. México: Trillas.

Filliozat, I. (2007). El corazón tiene sus razones. Conocer el lenguaje de las emociones. Barcelona: Urano.

Freud, S. (2008). El chiste y su relación con lo inconsciente. Madrid: Alianza editorial.

Kataria, M. (2021). Yoga de la risa. Ríe sin razón. México: Ediciones Obelisco.

Martín, R. (2007). The Psychology of humor: an integrative approach. Burlington: Elsevier Academic Press.

Moliner, M. (2001). Diccionario de uso del español. Madrid: Gredos. 
Planchart, E. (2006). Antropología de la risa, 1-54. https:/ / es.scribd.com/ document/274094535/ Planchart-Antropologi-a-de-la-Risa

Portilla, J. (1997). Fenomenología del relajo y otros ensayos. México: FCE.

Real Academia Española (RAE) (2020). Diccionario de la Lengua Española. https://dle.rae.es/ burla?m=form

Rogers, C. (2007). El proceso de convertirse en persona. Barcelona: Paidós.

Siurana, J. C. (2015). Ética del humor en la política y la educación. En Ortega, C.; Richart, A.; Páramo, V. y Ruíz, Ch. (Edts.) El mejoramiento humano. Granada: Editorial Comares.

Scott, J. (2000). Los dominados y el arte de la resistencia. México: Era.

Tajfel, H. (1984). Grupos humanos y categorías sociales. Barcelona: Herder.

Spilzinger, L. A. (2002) El uso del humor en la terapia. Psicoanálisis APdeBA, XXV(3), 587-596. http://www.diverrisa.com/uploads/documentos/Spilzinger\%5B1\%5D.pdf

Stevens, John (2006). El darse cuenta. Sangiago: Cuatro vientos.

Ziv, A. (1988). Teaching and Learning with Humor: Experiment and Replication. The Journal and Experimental Education, 57(1), 4-15. https:// www.tandfonline.com/doi/abs/10.108 $\underline{0 / 00220973.1988 .10806492}$ 